\title{
Sustainable Buildings: opportunities, challenges, aims and vision
}

\author{
John Kaiser Calautit* and Ben Richard Hughes \\ Department of Mechanical Engineering, University of Sheffield, \\ Sheffield, United Kingdom
}
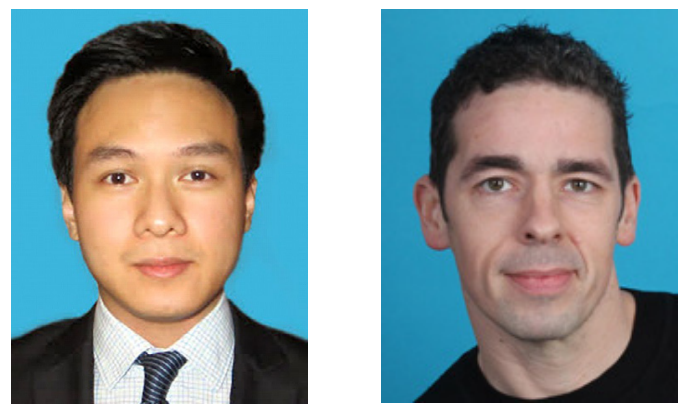

Welcome to Sustainable Buildings, a new international, peerreviewed, multi-disciplinary platform for the dissemination of knowledge and practice on engineering and technical issues concerning all aspects of building science, technology, energy and environmental performance, for the benefit of researchers and professional people concerned with building. In this editorial, we wish to outline the sustainability opportunities and challenges for the building sector, reasons for this endeavour and our vision for the types of research that we hope to see published over our term.

Over the past decade, international organisations have put significant effort towards the improvement of energy efficiency in new and existing buildings as evidenced by the new European Commission energy strategy for the period of 2020 to 2030 [1]. The building sector offers the greatest potential for achieving significant energy and $\mathrm{CO}_{2}$ reductions, at least cost, in developed and developing countries. Presently, the building sector contributes up to $40 \%$ of the global energy demand and one-third of $\mathrm{CO}_{2}$ emission [2]. The rise in population, demand for high comfort levels and time spent inside buildings assures that the increasing trend in energy consumption will continue in the future [3]. Therefore, it is essential to identify and develop innovation-integrated building and energy technologies in order to advance sustainable building practices and achieve the energy efficient targets.

The rapid development of new energy technologies [4], building materials [5], passive measures [6] and sensors [7] offers great opportunities for development of smart building systems that can serve multiple functions. However, such development would impose major challenges on the building industry sector as the design of buildings will change from design of individual components to integrated design of systems which fulfil multi-performance criteria and often contradictory requirements from energy efficiency, health, thermal comfort, aesthetics, structural, etc. [8]. To tackle such a multi-faceted problem, it requires the

\footnotetext{
*e-mail: j.calautit@sheffield.ac.uk
}

thoughtful integration between architecture, civil, mechanical, electrical, environmental and structural engineering, policy, social science and economic analysis.

Furthermore, responsible urbanisation practices at macro- and micro-levels can mitigate the negative effects of the built environment. The focus ranges from macro-level, starting from the sustainability of the planet, to the sustainability of immediate micro-levels, including economic sectors, municipalities, neighbourhoods, and on to levels encompassed in distinct buildings, components and materials, occupied spaces and surroundings along with individuals. There are changes in the environment surrounding building design that encourage an integrated and multi-disciplinary approach. As sustainability increasingly impacts upon the lives of corporations, individuals and wider society, the opportunities for responsible and holistic thinking are also increasing.

In recent years, a large and rapidly growing body of research in the built environment has involved multidisciplinary collaboration, a trend driven by the increased funding for multi-disciplinary projects and research institutes [9,10], along with the challenges and opportunities detailed previously. There is therefore more scope for disseminating the research output of these initiatives in a focused, effective and multi-disciplinary journal. Sustainable Buildings intends to fulfil this role and serve the diverse international community of engineers, architects, urban physicists, urban designers, researchers, scientists and industry professionals, providing a forum where each can communicate their original and innovative findings and provide motivation and direction towards meeting the current and future challenges of sustainable buildings. The journal will focus on advancing the knowledge on the forum of the global sustainability practices and to stimulate the exploration and innovations aimed at creating a climate resilient built environment that reduces energy consumption and environmental deterioration and creates high quality indoor environment.

We seek articles focusing on innovative research, rigorously analysed, verified and validated, related to the 
performance of buildings at different levels, ranging from city scale, neighbourhood and individual buildings, to building components and materials (Fig. 1).

Sustainable Buildings will publish original, interdisciplinary research articles, comprehensive reviews and short communications that demonstrate the work being conducted and developed by institutions and organisations from around the world. Articles on policies, problem identification and formulation and case studies on all aspects of buildings are also welcome. The journal will also publish selected papers from our partner international conferences related to sustainable buildings, for example, Sustainability in Energy and Buildings and the Zero Energy Mass Custom Home Network. Additionally, special issues on focused areas involving guest editors will also be offered.
Typical issues may contain contributions focusing on the following key subjects:

- passive, active and hybrid approach to building designs; - sustainable integration of the natural and built environment;

- sustainable building materials and construction: smart and novel building envelope;

- sustainable technologies and building integrated renewables;

- smart monitors and intelligent building controls;

- indoor environment quality, health and thermal comfort and human perception;

- building policies, green building codes and standards; - social and economic sustainability;

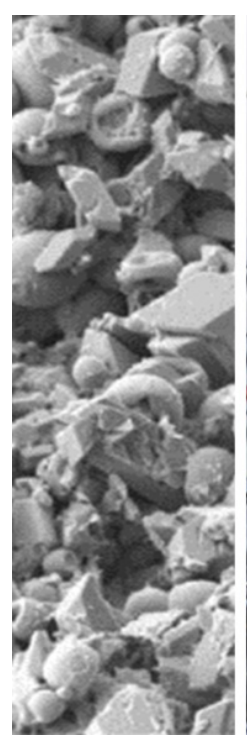

Material Scal

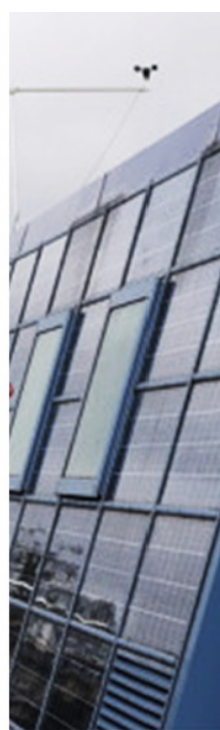

$\rightarrow$ Component
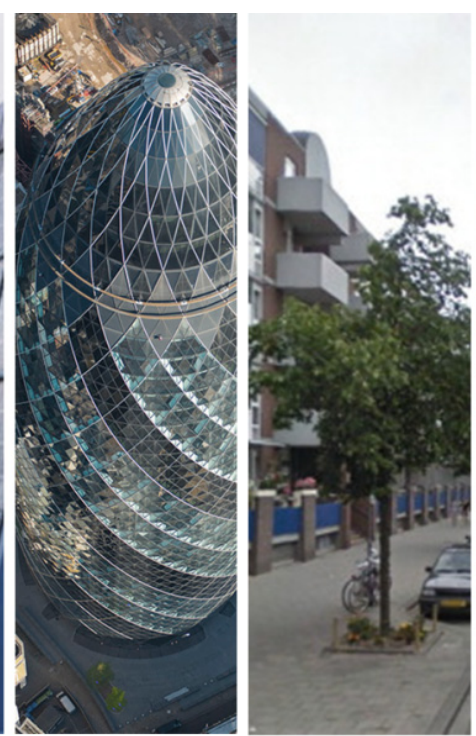

$\rightarrow$ Building

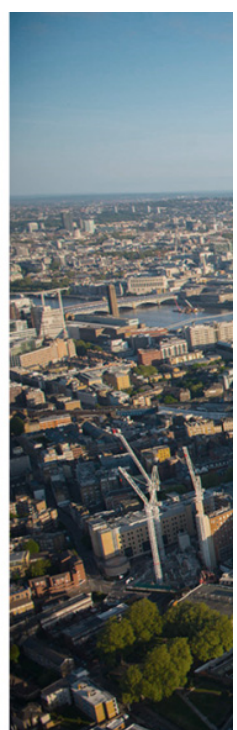

$\longrightarrow$ City Scale

Fig. 1. Multi-level building engineering [11-14].

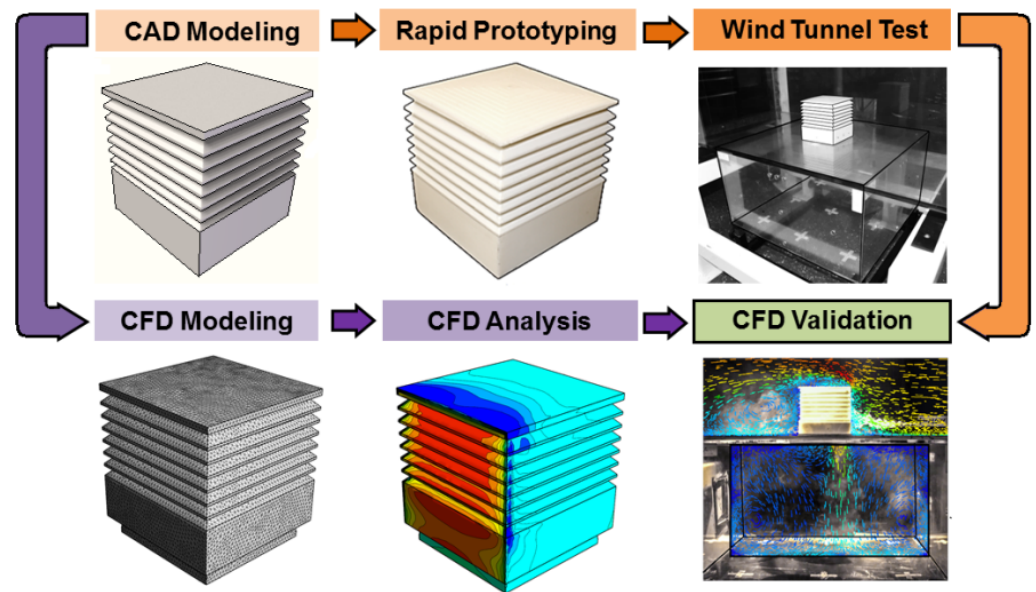

Fig. 2. A multi-disciplinary approach for the analysis of natural ventilation in buildings [18-20]. 


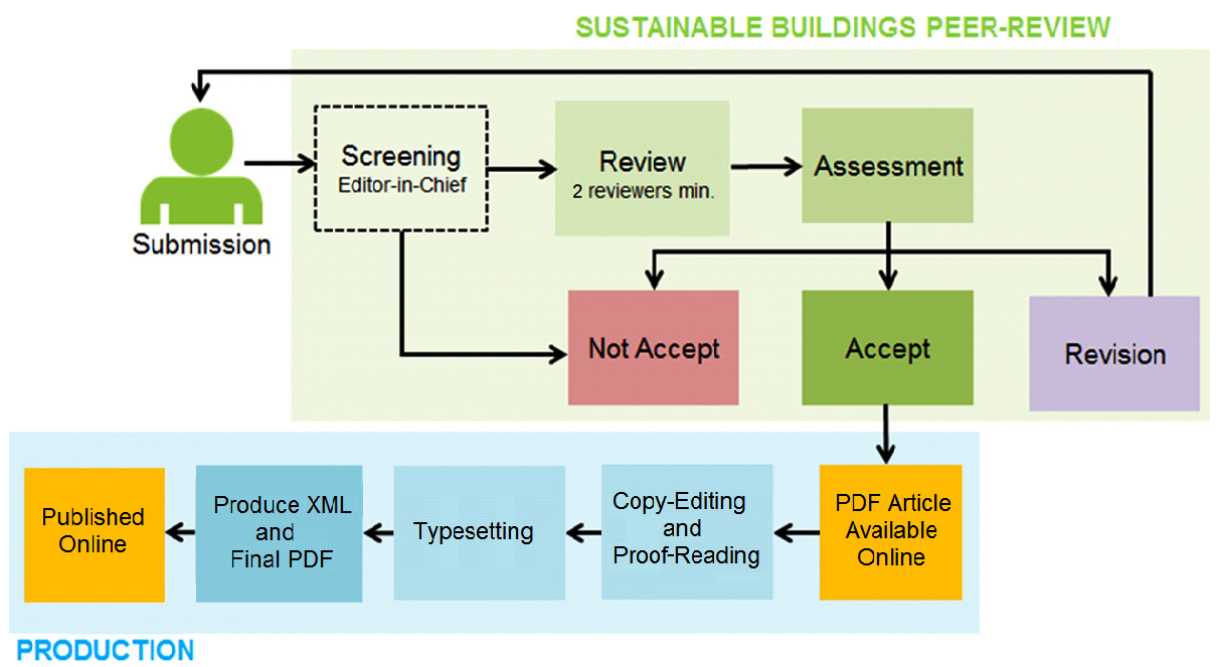

Fig. 3. Sustainable buildings editorial and production flow.

- climate mitigation and adaptation and resilience of buildings;

- modelling, simulation and optimisation of buildings.

A full list of topics covered by the journal is also available on the Sustainable Buildings website: www. sustainable-buildings-journal.org.

All relevant papers are carefully considered, vetted by a distinguished team of international experts, and rapidly published. Prospective authors are encouraged to explore the topics mentioned above, but are also free to submit their research in related fields. We encourage authors to publish their innovative ideas and findings in as much detail as possible. Inclusion of graphical abstracts, research highlights and supplementary materials such as datasets, 3D models, software, multimedia, videos, Google maps are encouraged to support and enhance your scientific work. To submit an article online, please visit: www.editorialman ager.com/sbuild or email us at contact-sbuild@edpsciences. org to discuss initial article ideas or ask questions about manuscript submission.

I am not alone in pioneering Sustainable Buildings. My colleague and Co-Editor-in-Chief is Dr. Ben Hughes, Reader in Energy, University of Sheffield. We will work together to provide you with the best forum possible to disseminate your research, read the latest ideas and innovation, identify and open up doors for potential collaborations. Dr Hughes is a Chartered Mechanical Engineer with over 20 years of combined academic and industrial experience; he is a Fellow of the Institution of Mechanical Engineers (IMechE), Sir Joseph Whitworth Senior Scholar, President of the Whitworth Society and the 2014 IMechE Visionary for outstanding leadership. Our expertise and the focus of our group's research in sustainable buildings are the development and commercialisation of innovative technologies for the urban environment such as passive cooling and heat recovery [15], stadium cooling [16] and heat island mitigation technology [17]. For a full list of references and further information on our expertise and interests, please visit my faculty profile and Figure 2 below shows an example of a research methodology we employ for the analysis of building technologies
Associate Editors of Sustainable Buildings: Mak CheukMing (Hong Kong Polytechnic University, Hong Kong), Hasim Altan (British University in Dubai, UAE), Hassam Chaudhry (Heriot Watt Univeristy, UK), Wangda Zuo (University of Miami, USA) and Masa Nagouchi (University of Melbourne, Australia) will lead our initiatives in Asia and Middle East, Europe, America and Australia, respectively. Our international editorial board (www.sustainablebuildings-journal.org/about-the-journal/editorial-board) contains a much broader scope of expertise.

Sustainable Buildings and the EDP Science production staff will pursue to publish articles as quickly as possible by adopting a rigorous and rapid review process. In most cases, this is a single-blind assessment with at least two independent reviewers, in addition to an Editor-in-Chief or Associate Editor, following which accepted articles are immediately converted into a PDF, assigned a digital object identifier (DOI) and published online. These articles are fully citable but will be replaced with typeset and copyedited versions at a later stage (Fig. 3).

This journal is published by the EDP Sciences, a not-forprofit publisher, established in 1920, belonging to five learned societies with a mission to participate in the dissemination of important researches that accelerates scientific progress and the cross-fertilisation of ideas. EDP Sciences is located in Paris and London and publishes over 55 scientific journals in the physical sciences, mathematics, life and environmental sciences, energy, materials and engineering, health and biomedical sciences. In 2013, EDP Sciences launched EDP Open, a platform dedicated to Open Access content. It also publishes 20 professional magazines, over 500 books, and 50 + conference proceedings annually through its custom-built platform, Web of Conferences.

EDP Sciences and myself, Dr Hughes, are committed to the highest standards of publishing integrity and academic honesty, providing authors with all the tools and services they need to showcase their work to an international audience.

Special recognition goes to Victoria Rae, Ariana Fuga and Agnès Henri at EDP Sciences for their valuable time and effort in developing and launching this journal and its website. 
On behalf of EDP Sciences, the associate editors and the editorial board, Ben and I are excited to introduce this new journal and we eagerly look forward to your submissions.

\section{References}

1. European Commission. Report on energy efficiency and its contribution to energy security and the 2030 framework for climate and energy policy, available at: http://eur-lex. europa.eu, 2014

2. WBCSD, Energy efficiency in buildings, available at: http:// www.wbcsd.org/buildings, 2009

3. L. Pérez-Lombard, J. Ortiz, C. Pout, A review on buildings energy consumption information, Energy Build 40, 394 (2008)

4. T.T. Chow, A review on photovoltaic/thermal hybrid solar technology, Appl. Energy 87, 365 (2010)

5. S.B. Sadineni, S. Madala, R.F. Boehm, Passive building energy savings: a review of building envelope components, Renew. Sustain. Energy Rev. 15, 3617 (2011)

6. B.R. Hughes, J.K. Calautit, S.A. Ghani, The development of commercial wind towers for natural ventilation: a review, Appl. Energy 92, 606 (2012)

7. A.I. Dounis, C. Caraiscos, Advanced control systems engineering for energy and comfort management in a building environment - A review, Renew. Sustain. Energy Rev. 13, 1246 (2009)

8. P. Heiselberg, Buildings-both part of the problem and the solution! Sustainability in Energy and Buildings, in Proceedings of the 4th International Conference in Sustainability in Energy and Buildings (SEB'12), 2013, p. 12-14

9. EPSRC, Our portfolio - Built Environment, available at: https://www.epsrc.ac.uk/research/ourportfolio/researchareas/ builtenv/, 2015
10. Innovate UK, Built Environment, available at: https:// connect.innovateuk.org/web/modernbuiltktn/funding, 2015

11. F. Kuznik, D. David, K. Johannes, J.-J. Roux, A review on phase change materials integrated in building walls, Renew. Sustain. Energy Rev. 15, 379 (2011)

12. E.A. Essah, A.R. Arguelles, N. Glover, Assessing the performance of a building integrated BP c-Si PV system, Renew. Energy 73, 36 (2015)

13. C. Gromke, B. Blocken, W. Janssen, B. Merema, T. van Hooff, H. Timmermans, CFD analysis of transpirational cooling by vegetation: Case study for specific meteorological conditions during a heat wave in Arnhem, Netherlands, Build. Environ. 83, $11(2015)$

14. Ibtimes, Night and day: spectacular aerial photos of London by Jason Hawkes, available at: http://www.ibtimes.co.uk/ night-day-spectacular-aerial-photos-london-by-jasonhawkes-1449433, 2014

15. D. O'Connor, J.K. Calautit, B.R. Hughes, A study of passive ventilation integrated with heat recovery, Energy Build. 82, $799(2014)$

16. P. Sofotasiou, B.R. Hughes, J.K. Calautit, Qatar 2022: facing the FIFA World Cup climatic and legacy challenges, Sustain. Cities Society 14, 16 (2015)

17. D. Nasir, B.R. Hughes, J.K. Calautit, A study of the impact of building geometry on the thermal performance of road pavement solar collectors, Energy 93, 2614 (2015)

18. J.K. Calautit, B.R. Hughes, Measurement and prediction of the indoor airflow in a room ventilated with a commercial wind tower, Energy Build. 84, 367 (2014)

19. J.K. Calautit, D. O'Connor, B.R. Hughes, Determining the optimum spacing and arrangement for commercial wind towers for ventilation performance, Build. Environ. 82, 274 (2014)

20. J.K. Calautit, B.R. Hughes, Wind tunnel and CFD study of the natural ventilation performance of a commercial multidirectional wind tower, Build. Environ. 80, 71 (2014)

Cite this article as: J.K. Calautit and B.R. Hughes: Sustainable Buildings: opportunities, challenges, aims and vision. Sust. Build. 1, E1 (2016) 